\title{
ROBOTICALLY ASSISTED ENDOSCOPIC CORONARY ARTERY BYPASS PROCEDURES WITHOUT CARDIOPULMONARY BYPASS
}

Hermann Reichenspurner, MD, PhD, Dieter H. Boehm, MD, PhD, Helmut Gulbins, MD, Christian Detter, MD, Ralph Damiano, MD, Michael Mack, MD, and Bruno Reichart, MD, Munich, Germany

Minimally invasive coronary artery surgical procedures still require a minithoracotomy or partial sternotomy for the coronary artery anastomosis. The clinical performance of manual endoscopic coronary artery grafting is extremely difficult and has not been published yet. For this reason, computer-assisted systems have been developed to facilitate endoscopic microsurgery. ${ }^{1}$ This is the description of the first clinical use of the voice-controlled and computer-assisted system ZEUS (Computer Motion Inc, Goleta, Calif) for endoscopic coronary artery surgical procedures on the beating heart without cardiopulmonary bypass.

Four patients ( 3 men and 1 woman, aged 44 to 64 years) with an isolated proximal stenosis of the left anterior descending (LAD) coronary artery were evaluated for the procedure. After approval by the local ethics committee, written informed consent was given by the patients. At surgery, 3 thoracoscopic ports $(10 \mathrm{~mm}$ and $5 \mathrm{~mm})$ were inserted in the left side of the chest. First, the left internal thoracic artery (LITA) was dissected endoscopically. After this, a small parasternal incision $(4 \mathrm{~cm})$ was made above the 5 th intercostal space. The pericardium was incised through the minithoracotomy. The LAD was visualized and the Octopus system (Medtronic GmbH, Düsseldorf, Germany) was used for coronary artery stabilization. One stabilization pod was inserted through the incision and the second one through one of the thoracoscopic ports. The ZEUS Robotic Surgical System was used to perform an endoscopic graft anastomosis. This system consists of 3 interactive robotic arms placed at the operating table, a computer controller, and an ergonomically enhanced surgeon console. One robotic arm was used to position the endoscope by means of voice control, and the other 2 robotic arms manipulated the surgical instruments under the surgeon's direct control. A 3-dimensional camera (Vista Cardiothoracic Systems Inc, Westborough, Mass) was inserted through the minithoracotomy. The 2 instrument controllers were inserted through 2 of the thoracoscopic ports

From the Department of Cardiac Surgery, University Hospital Grosshadern, Munich, Germany.

Received for publication June 23, 1999; accepted for publication July 27, 1999.

Address for reprints: Hermann Reichenspurner, MD, PhD, Department of Cardiac Surgery, University Hospital Grosshadern, Marchioninistr 15, D-81377 Munich, Germany (E-mail: hcr@hch.med.uni-muenchen.de).

J Thorac Cardiovasc Surg 1999;118:960-1

Copyright (C) 1999 by Mosby, Inc.

$0022-5223 / 99 \$ 8.00+0 \quad \mathbf{1 2 / 5 4 / 1 0 1 7 3 8}$

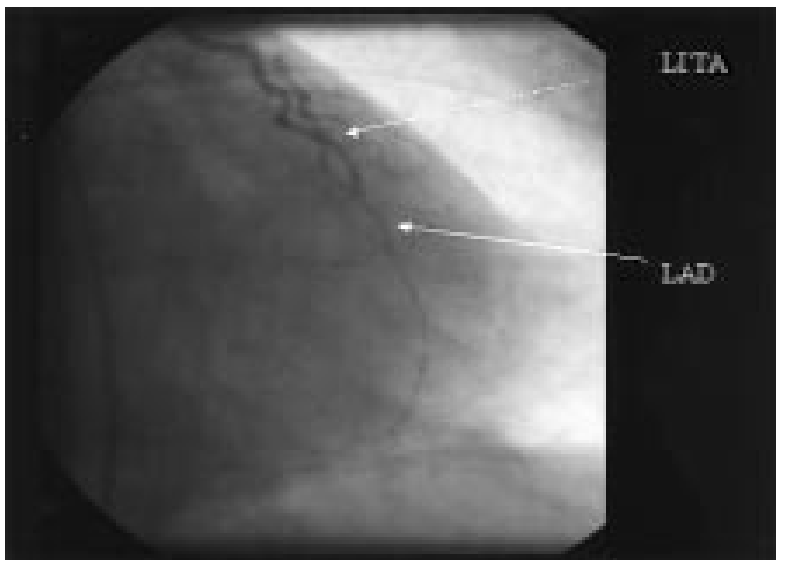

Fig 1. Postoperative angiogram, 4 weeks after off-pump coronary artery surgery performed with the ZEUS system, demonstrating a patent thoracic artery (LITA) bypass to the LAD.

and connected to the robotic arms. After temporary occlusion of the LAD with 2 vessel loops, the artery was incised. The endoscopic coronary artery anastomosis of the LITA to the LAD was done in an end-to-side fashion with a 7-0 polytetrafluoroethylene* suture using the ZEUS Robotic System through the thoracoscopic ports on the beating heart.

In 1 patient the operation was converted to a manual coronary artery bypass procedure because of a small LAD $(<1.5$ $\mathrm{mm}$ ). This procedure was done like a minimally invasive direct coronary artery bypass (MIDCAB) operation through a slightly larger minithoracotomy. For the remaining 3 patients, the different durations of the surgical procedure, time spent in the intensive care unit, and total hospitalization time are listed in Table I.

Immediately after the anastomosis, the flow through the coronary artery and the LITA was released and LITA flow was measured with an ultrasonic probe, revealing flows between 49 and $110 \mathrm{~mL} / \mathrm{min}$ (Cardiomed Inc, Oslo, Norway). There were no intraoperative complications, such as evidence of myocardial ischemia or hemodynamic deterioration. Each patient had an uneventful intraoperative and postoperative course and was discharged home 5 to 7 days after the operation. Angiographic follow-up performed 4 to 6 weeks after the operation demonstrated patent anastomoses without any evidence of stenosis or kinking (Fig 1).

The ultimate goal of minimally invasive coronary artery

*W. L. Gore \& Associates, Inc, Flagstaff, Ariz. 


\section{Table I}

\begin{tabular}{lccc}
\hline & \multicolumn{3}{c}{ Patient No. } \\
\cline { 2 - 4 } & 1 & 2 & 3 \\
\hline Endoscopic LITA takedown time (min) & 93 & 110 & 58 \\
Coronary artery occlusion (min) & 53 & 42 & 33 \\
Endoscopic anastomosis time (min) & 39 & 30 & 24 \\
Time of ventilation (h) & 6.5 & 8.0 & 3.5 \\
ICU stay (h) & 18 & 14 & 12 \\
Hospitalization (d) & 7 & 6 & 5 \\
\hline
\end{tabular}

LITA, Left internal thoracic artery; ICU, intensive care unit.

surgery is the elimination of both the surgical incision and the need for cardiopulmonary bypass. The feasibility of endoscopic coronary artery surgery on the arrested heart has been reported previously with the use of computer-enhanced robotic systems. ${ }^{2,3}$ This is the first clinical report of an endoscopic coronary artery anastomosis that was performed on the beating heart with the use of endoscopic stabilizers and a surgical robotic system. Although a small minithoracotomy was still done for safety reasons, the feasibility of an offpump endoscopic anastomosis was demonstrated, which represents a significant step toward the development of the desired minimally invasive approach for the surgical treatment of coronary artery disease.

\section{REFERENCES}

1. Stephenson ER, Sankholkar S, Ducko CT, Damiano RJ. Robotically-assisted microsurgery for endoscopic coronary artery bypass grafting. Ann Thorac Surg 1998;66:1064-7.

2. Reichenspurner H, Damiano RJ, Mack M, Boehm DH, Gulbins $\mathrm{H}$, Detter $\mathrm{C}$, et al. Use of the voice-controlled and computerassisted surgical system ZEUS for endoscopic coronary artery bypass grafting. J Thorac Cardiovasc Surg 1999;118:11-6.

3. Mohr F, Falk V, Diegeler A, Autschbach R. Computer-enhanced coronary artery bypass surgery. J Thorac Cardiovasc Surg 1999; 117:1212-4. 